\title{
Urban Irrigation Suppresses Land Surface Temperature and Changes the Hydrologic Regime in Semi-Arid Regions
}

\author{
Bryant Reyes ${ }^{1,2} \mathbb{D}$, Terri Hogue ${ }^{1,2, *}$ and Reed Maxwell ${ }^{2,3} \mathbb{D}$ \\ 1 Department of Civil and Environmental Engineering, Colorado School of Mines, Golden, CO 80401, USA; \\ brreyes@mines.edu \\ 2 NSF Engineering Research Center for Reinventing the Nation's Urban Water Infrastructure, Colorado School \\ of Mines, Golden, CO 80401, USA; rmaxwell@mines.edu \\ 3 Department of Geology and Geological Engineering, Colorado School of Mines, Golden, CO 80401, USA \\ * Correspondence: thogue@mines.edu; Tel.: +1-303-384-2588
}

Received: 2 October 2018; Accepted: 30 October 2018; Published: 2 November 2018

\begin{abstract}
Outdoor water use for irrigation constitutes a substantial urban water flux yet its impact on the land surface remains poorly quantified. This study analyzes the impact of irrigation on land surface temperatures and the hydrologic regime of a large, semi-arid urban metropolis. Using remotely sensed products, municipal water use data, and simulations with a coupled land surface-hydrologic model we find significant impacts on both land surface temperatures and the hydrologic dynamics of the study domain, Los Angeles, CA. The analysis of remotely sensed land surface temperature finds a decrease of up to $3.2 \pm 0.02 \mathrm{~K}$ between low and high irrigation areas of similar land cover. These temperature differences, caused by a human-induced flux, are on par with estimates of the urban heat island effect and regional warming trends; simulations are able to capture this difference but underestimate absolute values throughout. Assessment of change in irrigation volume and timing through simulations show that irrigation timing has a small impact $(< \pm 2 \%)$ on evapotranspiration and runoff. Furthermore, relatively low irrigation volumes push the semi-arid urban environment into a sub-humid regime.
\end{abstract}

Keywords: urban hydrology; water-use; land surface temperature

\section{Introduction}

Outdoor water use, or urban irrigation, has often been overlooked in typical studies of the urban hydrologic environment. In semi-arid regions, however, outdoor water use accounts for a large percentage of potable domestic water use (at times eclipsing indoor water use) providing a significant input to the urban water budgets of these areas [1,2]. Exacerbating the issue of water sustainability, urbanization is most rapidly occurring in regions of the world that are less equipped to handle the process [3,4], increasing the water resource stress in already water-stressed environments. Many municipalities in these regions have implemented water sustainability plans and have stated goals of reducing imported water volumes by increasing use of sustainable local sources of water (often local groundwater), re-using wastewater, and reducing outdoor water use [4-6]. Since outdoor water use can be a significant input of water to semi-arid urban hydrologic systems [2,7], any change in the flux can be expected to have impacts on hydrologic and energy balances, yet quantification of these effects is lacking.

Much of what can be found in the literature regarding irrigation's effect on the land surface originates from the climate and agricultural sciences communities and pertains to agricultural settings at large regional scales. These studies [8-14] generally conclude that irrigation significantly alters 
the climate regime and may even be masking the effects of global warming in these regions due to the "irrigation cooling effect". This cooling effect is the shift in the Bowen ratio from sensible to latent heating caused by increased soil moisture. The strong coupling of atmospheric processes with soil moisture (and by extension irrigation) have been shown in a variety of natural domains as well [15-18]. Recent studies [19-25] have also begun to examine irrigation's effect on the urban hydrologic environment by utilizing a variety of approaches and conclude that the effect of irrigation is largely dependent on the prevailing regional climatic and hydrologic regimes (i.e., irrigation may have a much larger influence on the recharge rates of arid and semi-arid cities).

Various other hydrologic fluxes in urban environments have been identified in the literature [22,26-30]; however, the scientific understanding of these processes varies. Urban-specific fluxes, such as leaking infrastructure and outdoor water use, can increase recharge to groundwater systems in many semi-arid cities [20,31-34] as well as impact the surface energy budget [35,36]. Assessing the long-term hydrologic impacts of changing anthropogenic fluxes remains difficult using conventional methods. Recent use of Budyko $[37,38]$ space and water-energy partitioning plots $[39,40]$ have assessed the relative impacts of land cover (LC), climate, and human induced changes on the hydrologic regimes of watersheds around the globe.

The hydrometeorologic and atmospheric sciences communities have also studied the impacts of urban areas on regional climate, most prominently through the urban heat island (UHI) effect [41-48]. Vahmani and Ban-Weiss [49] show the effects of drought resistant vegetation and associated changes in irrigation patterns on air temperature utilizing a mesoscale weather model over Los Angeles. Day-time increases in temperature are simulated along with decreases in night-time temperatures. A study across 89 cities in India described the existence of the urban cool island (UCI) in cities located in arid and semi-arid environments [50]. These studies provide important insights into the processes altered by urbanization and, when implemented into integrated models of the urban environment, improve scientific understanding while guiding policies for more sustainable cities. However, they often fail to analyze the heterogeneities within the urban domain at higher resolutions $(<1 \mathrm{~km})$ by focusing on temperature differences between rural areas and cities as a whole [51-54]. This leaves a gap in understanding of the effects of anthropogenic fluxes on otherwise similar land surfaces within the city. Questions abound regarding the heterogeneity presented by cities (residential areas, urban parks, industrial regions, downtowns, etc.) and the processes that cause and produce them.

The purpose of the current study is to understand some of the impacts of irrigating the semi-arid urban land surface and assess the changes that may occur under various irrigation scenarios. By analyzing domestic water use data, satellite remote sensing observations, and using an integrated hydrologic and land surface modeling we find that, irrespective of LC, the effects of outdoor water use are wide ranging causing changes to the hydrologic regime of the system. We seek to answer the following questions in our work: (1) Are differences in land surface temperature (LST) detectable between irrigated and non-irrigated areas of similar LC within a semi-arid urban environment and how do these differences manifest? Can we accurately model these differences using an integrated hydrologic and land surface model? And (2) What impact does irrigation have on the hydrologic and energy fluxes of typical urban LC types when applied at various irrigation rates and times of day? How do various scenarios of urban irrigation alter the hydrologic regime of urban semi-arid environments?

\section{Methods}

LST and hydrologic changes due to urban outdoor water use are evaluated using remotely sensed products, municipal data, and an integrated hydrologic and land surface model applied throughout an 11-year study period. This provides insight into the significant urban irrigation flux in semi-arid regions while advancing the implementation of physical hydrologic models in urban environments. This section provides a description of the methods used in this study. 


\subsection{Area of Interest}

The area of interest, Ballona Creek watershed in Los Angeles, California, is a highly urbanized domain covering approximately $231 \mathrm{~km}^{2}\left(89 \mathrm{mi}^{2}\right)$ above the USGS gauge [55]. The City of Los Angeles resides in a semi-arid Mediterranean climate with a large percentage of total precipitation occurring in the fall and winter months and a comparatively dry spring and summer. The northern stretches of the watershed consist of the Santa Monica Mountains with the rest of the watershed encompassing parts of Downtown Los Angeles and cities and neighborhoods to the west. The region reached its current level of urbanization around the 1950's exhibiting water use and management patterns that include: large amounts of imported water ( $85 \%$ of total water supply) [56]; high domestic, municipal and commercial outdoor water use ( $60 \%$ of their total water use) [56]; and a storm sewer system and channelized surface water networks designed for efficient flood mitigation. These water use and management patterns are characteristic, to varying degrees, of other urban semi-arid regions in developed countries in the past 70 years or so.

\subsection{Landsat Land Surface Temperature}

Atmospherically corrected Landsat 5 TM and Landsat 7 ETM+ data (obtained from the LEDAPS project) [57] from 1 January 2000 through 31 December 2010 are used for land surface temperature (LST) estimation in this study. Utilizing the physical relationship between sensor brightness temperature $\left(T_{B}\right)$ and the emissivity $(\varepsilon)$ of a surface as given by Artis and Carnahan [58], LST is estimated as follows:

$$
\mathrm{LST}=\frac{T_{B}}{1+\left(\frac{\lambda T_{B}}{\alpha}\right) \ln \varepsilon}
$$

where $\lambda$ is the mean of the wavelength of emitted radiance ( $11.45 \mu \mathrm{m}$ for Band 6 of Landsat 5 and 7$)$ and $\alpha$ is a combination of the Planck, speed of light, and Boltzmann constants $\left(\alpha=h c / k=1.44 \times 10^{-2}\right)$. At sensor brightness temperature of the surface in the thermal range is obtained from Band 6 of the instruments. To estimate emissivity, we use the Normalized Difference Vegetation Index (NDVI, defined as [Band 4- Band 3] / [Band 4 + Band 3]) threshold method as developed by Sobrino et al. [59] and modified for the urban domain by Stathopoulou et al. [60]. Pixels with an NDVI of less than $0.2, N D V I_{\text {min }}$, are assumed to have full urban built coverage and are assigned an emissivity of 0.92. Fully vegetated pixels are assumed to be those that have an NDVI of 0.5 or greater, $N D V I_{\max }$, and have an emissivity set to 0.99 . Mixed pixels utilize the greenness vegetation fraction, also termed the proportion of vegetation coverage, $P_{v}$, in a mixing model to calculate emissivity as follows:

$$
\varepsilon=\left\{\begin{aligned}
\varepsilon_{g}=0.92, & N D V I<0.2 \\
0.026 P_{v}+0.964, & 0.2 \leq N D V I<0.5 \\
\varepsilon_{v}=0.99, & N D V I \geq 0.5
\end{aligned}\right.
$$

$P_{v}$ is calculated using the NDVI of the pixel as follows:

$$
P_{v}=\left[\frac{N D V I-N D V I_{\min }}{N D V I_{\max }-N D V I_{\min }}\right]^{2}=\left[\frac{N D V I-0.2}{0.5-0.2}\right]^{2}
$$

Using this method, and masking out pixels with cloud and shadow cover, we obtain 364 useful Landsat 5 and 7 scenes within the study period. These LST values are aggregated by LC and irrigation rate for each month and year in the study period as described in Section 2.4 below.

\subsection{Outdoor Water Use Data and LST Classification}

To analyze the impacts of urban irrigation on LSTs of various urban LCs, we first need to classify each of the pixels in each scene by LC type and water use rate. Both USGS National Land 
Cover Database (NLCD) 2001 [61] and 2006 [62] were used to classify pixels into the four urban LC types throughout the time period; these are "Developed, Open Space", "Developed, Low Intensity", "Developed, Medium Intensity" and "Developed, High Intensity". Next, we use monthly water use data obtained from the Los Angeles Department of Water and Power (LADWP) to classify high and low outdoor water use areas. This data [2] is aggregated by census tract and contains monthly total water use data for single-family homes in the LADWP service area from January 2000 through 2010. Using the minimum use method [63] we estimate outdoor water use for each month. We then classify the high water-users as those in the top 25th percentile and low outdoor water users as those in the bottom 25th percentile of water-use for each month. This creates a total of 8 combined LC and water use classes that change each month given the addition of low and high water-use areas of high, medium, low intensity developed, and developed open space. This classification and methodology are shown for a typical month in Figure 1.

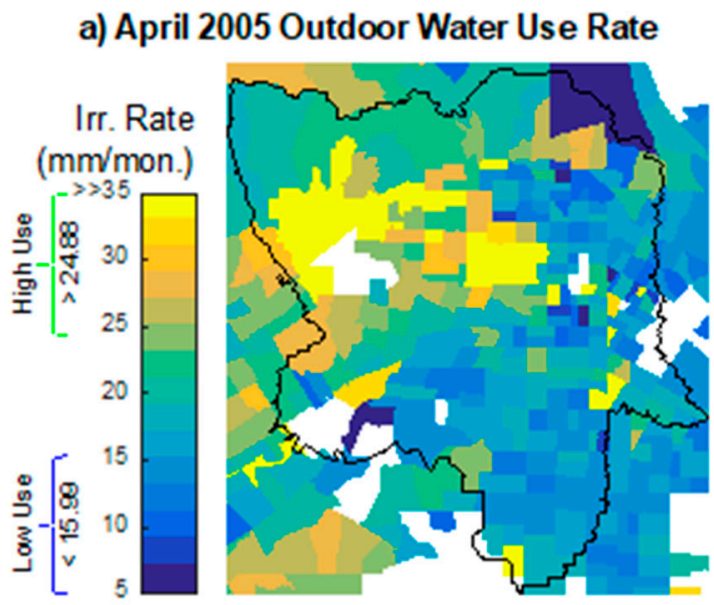

\section{b) Land Cover \& High/Low Water Use Areas}
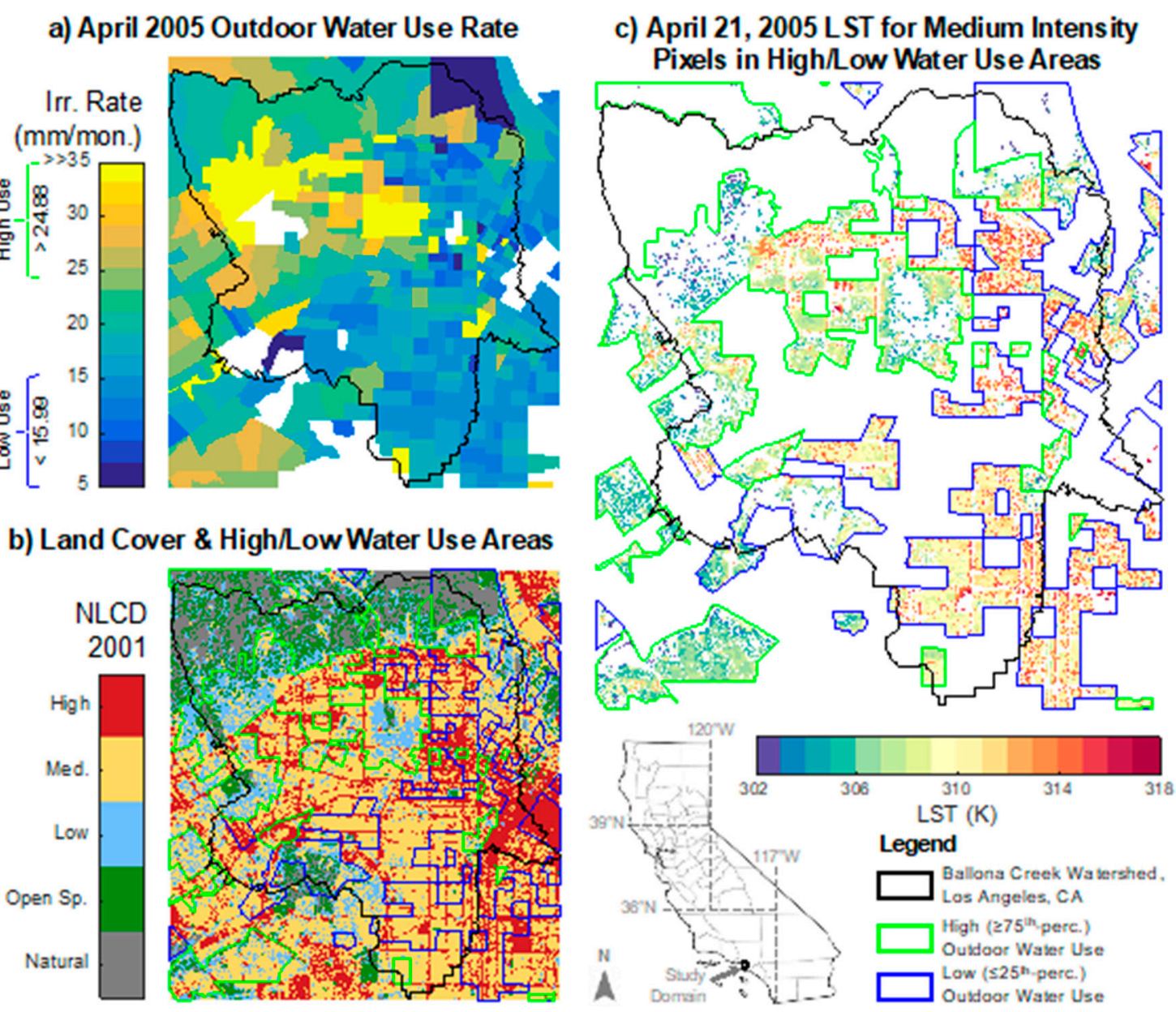

Figure 1. Study domain and land surface temperature classification methodology: (a) Estimated outdoor water use data for a typical month (April 2005), (b) high and low water use areas overlying the NLCD 2001 land cover (Developed, High Intensity; Developed; Medium Intensity; Developed; Low Intensity; Developed; Open Space; "Natural" refers to all other land cover), (c) medium intensity developed LST pixels from the 21 April 2005 Landsat overpass within high and low water use areas.

\subsection{Land Cover, Irrigation and Model Used}

The hydrologic and land surface model used for this work is PF.CLM [16,64-67] which consists of ParFlow (PF) [68-71] coupled to a version of the Common Land Model (CLM) [72,73]. PF.CLM models variably saturated groundwater and overland flow using the three-dimensional Richards' equation [74] with surface water equations integrated into Richards' equation through the use of an overland 
flow boundary condition and the assumption of pressure continuity between the surface-subsurface systems as described by Kollet and Maxwell [70]. For detailed discussion of the coupling philosophy and governing equations in PF.CLM please refer to the aforementioned papers. Irrigation in the model is represented as "spray irrigation", a suitable proxy to the typical methods seen in domestic applications. The application of water above the vegetation canopy allows the model to account for canopy interception, throughfall, runoff, and infiltration as irrigation occurs [75-77].

The top model layer is represented as one of four LC types established to represent the heterogeneity in the urban environment. These are the USGS NLCD 2001 [61] and 2006 [62] urban LC types: "Developed, Open Space", "Developed, Low Intensity", "Developed, Medium Intensity" and "Developed, High Intensity". These four urban LC types correspond with ranges of imperviousness used to produce effective soil parameters for the model. The land surface component of our model adapts the typical soil-vegetation-atmosphere transfer (SVAT) scheme for urban surfaces as described by Masson [43]. Land surface parameterization for urban soils and LC types have been produced in previous work [78] and are used in this study.

A single column domain is used to conduct an analysis on the sensitivity of land surface and hydrologic fluxes. This consists of a single homogenous $30 \mathrm{~m} \times 30 \mathrm{~m}$ grid box with 15 subsurface layers of variable thickness reaching a depth of $84 \mathrm{~m}$ below the surface. The bottom 14 layers are modeled as sandy loam with the top layer corresponding to one of the 4 NLCD urban LC types described above. The water table is initialized at $34 \mathrm{~m}$ below the surface (at layer 13) and the hydrology of the system is spun-up for each irrigation rate and LC until the change in storage is less than $1 \%$ ( 15 years) per Ajami et al. [79]. Using this steady-state pressure field we spin-up the land surface model using the first 2 years of the forcing data (plus irrigation), then run the simulations again using the full 11 years of forcing data for analysis. The irrigation rates are calculated using the average precipitation rate for the 11-year period from 2000 through 2010 (397 $\mathrm{mm}$ year $\left.{ }^{-1}\right)$. Thirteen irrigation rates are tested (Table 1) ranging from no outdoor water use up to $1192 \mathrm{~mm}^{-1} \mathrm{r}^{-1}$, or $300 \%$ of average precipitation. To test the sensitivity of irrigation timing in the model, simulations with irrigation applied at varying times of the day (12 am, $6 \mathrm{am}, 12 \mathrm{pm}$, and $6 \mathrm{pm}$ local times) for one hour every other day are completed. In total, this study completed 196 simulations.

Table 1. Total yearly irrigation and irrigation plus precipitation rates for all simulations. Irrigation is applied for 1 hour every other day at the specified hour of the simulation $(00,06,12$, or 18 local time).

\begin{tabular}{|c|c|c|c|c|c|c|c|c|c|c|c|c|c|}
\hline Scenario & Base & $5 \%$ & $10 \%$ & $25 \%$ & $50 \%$ & $75 \%$ & $100 \%$ & $125 \%$ & $150 \%$ & $175 \%$ & $200 \%$ & $250 \%$ & $300 \%$ \\
\hline Irrigation Rate $\left(\mathrm{mm} \mathrm{yr}^{-1}\right)$ & 0 & 20 & 40 & 99 & 199 & 298 & 397 & 496 & 596 & 695 & 794 & 993 & 1192 \\
\hline Precipitation + Irrigation $\left(\mathrm{mm} \mathrm{yr}^{-1}\right)$ & 397 & 417 & 437 & 496 & 596 & 695 & 794 & 893 & 993 & 1092 & 1191 & 1390 & 1588 \\
\hline
\end{tabular}

\subsection{Model Forcings}

North American Land Data Assimilation System (NLDAS) [80] hourly meteorological forcings were obtained for the period from 1 January 2000 through 31 December 2010 for the "Downtown Los Angeles" pixel at UTM 11N 378833.47 3769919.25. We replaced NLDAS precipitation with observations from a network of 43 Los Angeles Department of Public Works (LADPW), 18 National Climatic Data Center (NCDC), and 6 California Irrigation Management Information System (CIMIS) precipitation gauges in Los Angeles County. A simple inverse distance weighting (IDW) method (with an alpha set at 3) [81] was used to spatially interpolate the precipitation data to the center point of our NLDAS forcing pixel. In aggregate, these hourly forcings include: precipitation rate $\left[\mathrm{mm} \mathrm{s}^{-1}\right]$, air temperature $[\mathrm{K}]$; atmospheric pressure [Pa], water-vapor specific humidity $[-], \mathrm{U}-$ and $\mathrm{V}$-components of wind $\left[\mathrm{m} \mathrm{s}^{-1}\right]$, and short-wave and long-wave radiation $\left[\mathrm{W} \mathrm{m}^{-2}\right]$ all estimated at standard heights (i.e., $2 \mathrm{~m}$ above the land surface). A digital elevation model was obtained from the USGS's National Elevation Dataset [82] at a $30 \mathrm{~m}$ spatial resolution and was used to calculate the average slope of the watershed $(\sim 0.02)$ for the simulations. 


\section{Results}

\subsection{Irrigation Impact on LST}

In order to assess the impact of the irrigation flux on various urban LC, we classify the remotely sensed LST values based on the 4 urban NLCD LC types (developed open space, low intensity developed, medium intensity developed, and high intensity developed), estimations of high and low outdoor water use rates in the Ballona Creek domain, and month of the year (Figure 1). The City of Los Angeles began to place restrictions on the amount of domestic water use allowed in the city beginning in 2008. Although this restriction in water use does not significantly appear in our aggregated water use data, we decided to limit the scope of the analysis to the pre-water restriction years (2000 through 2007). Water restriction rules are often inconsistently implemented and enforced throughout the city, therefore including these post-water restriction years in the analysis might introduce a bias in the results.

Figure 2 displays comparisons of the Landsat-derived [57] remotely sensed LST values, aggregated for pre-water restriction year months (from January 2000 through December 2007). Each box-plot constitutes an average of 2-3 Landsat scenes for each month with $\sim 20,000-150,000+$ individual $30 \mathrm{~m}$ pixels (data points) per class. This data was tested for normality using the Kolmogorov-Smirnov test and for equal variance using Bartlett's test. We find that nearly all months and all urban LC types exhibit a statistically significant decrease in LST from low to high water use areas even through the spatial and temporal variability exhibited by the LST values.

Applying an unpaired Student's $t$-test to each month of data yields a statistically significant $(p<0.01)$ decrease in LST from low irrigated areas to highly irrigated areas, generally irrespective of LC and month of the year (see Figure 2 and monthly differences shown above each box plot). This decrease in LST ranges from $0.3 \mathrm{~K}$ in February for high intensity developed areas to $3.2 \mathrm{~K}$ in May for medium intensity areas. Decreases in LST are most prominent during spring (May/April/May) and summer (June/July/August) months likely due to the decrease in precipitation as compared to the fall and winter months in the Los Angeles area. Average decreases for developed open space, low, medium, and high intensity developed during these months are $2.1 \mathrm{~K}, 2.4 \mathrm{~K}, 2.9 \mathrm{~K}$, and $1.2 \mathrm{~K}$ respectively. Medium intensity LC shows the largest decrease, perhaps due to the wide range of land uses within this LC type. These decreases in LST are large and are in similar ranges to increases in air temperature caused by the UHI [41-43,47,48,52-54], similar decreases between rural-urban areas caused by the UCI [50], and projected increases caused by climate change [83].

In an attempt to separate the potential climate effects from the anthropogenic signal, we look at LST values from a dry year (water year 2002 with $135 \mathrm{~mm}$ total precipitation) and a wet year (water year 2005 with $966 \mathrm{~mm}$ total precipitation) in the study area. We compare LST values for each month in the water year (Figure 3) for low intensity developed LC and show the mean differences for all urban LC types (Table 2). Again, there is a general decrease in mean LST for all LCs and months, however the larger decreases in LST during the dry year, during seasons when irrigation is greater, and when precipitation decreases points to the irrigation flux as the likely cause of the decrease. For instance, the average decrease in mean LST for the spring and summer months for developed open space is $1.1 \mathrm{~K}$ during the wet year but increases to $2.4 \mathrm{~K}$ during the dry year. Spring and summer month mean LST decreases for low, medium, and high intensity developed LCs for these two years are 1.4/2.7 K (wet/dry), 2.4/3.4 K (wet/dry), and 1.0/1.5 K (wet/dry) respectively. These values both show how the anthropogenic signal varies in each LC type and help establish upper and lower limits on the impact of outdoor water use on LSTs. 

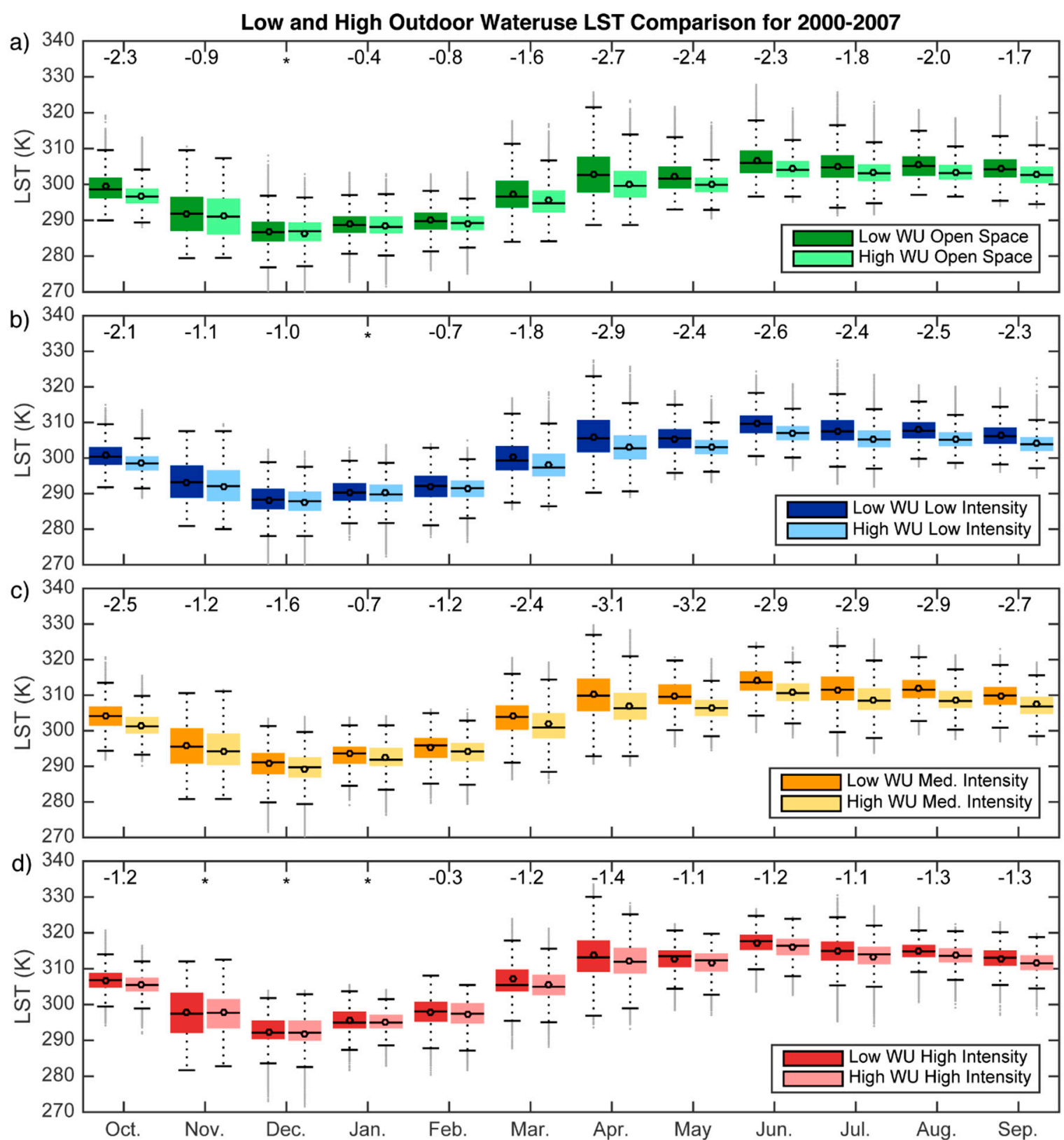

Figure 2. Box plots of monthly LST pixels aggregated across years for (a) Developed, Open Space, (b) Developed, Low Intensity, (c) Developed, Medium Intensity, and (d) Developed, High Intensity land cover. The box represents the middle $50 \%$ of data, line and circle within the box are the median and mean respectively, the whiskers encompass $96 \%$ of the data, and the points are outliers. Mean difference between urban land cover in low (dark color) and high (light color) water use areas for pre-water use restriction years $(1 / 2000$ through $12 / 2007)$ is shown above the box plot for each month. All mean differences are significant $(p<0.01)$ except for those with an asterisk $\left.{ }^{*}\right)$.

Our study period also includes periods of varying outdoor water use restrictions throughout the domain in years 2008, 2009, and 2010 [84]. However, consistent changes between mean LST difference of pre- and post-water restriction years were not detected in the data. We hypothesize this may be due to varying degree of success in implementation of water use restriction throughout these years and possible lag in LST response to outdoor water use change. 


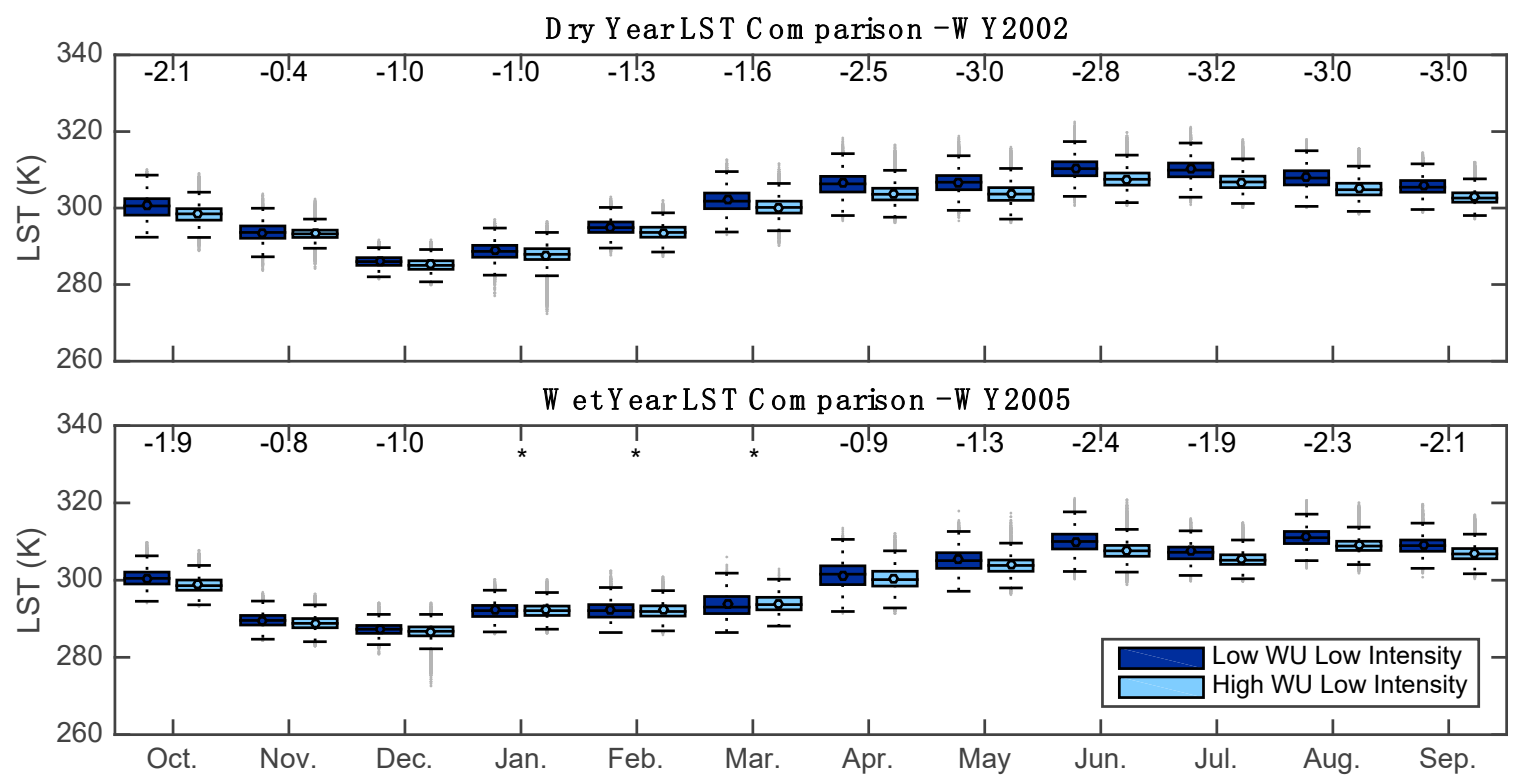

Figure 3. Box plots for low and high water-use areas of low intensity LC. Similar to Figure 2 for a (top) dry year and (bottom) wet year. During the spring and summer months of the dry year, irrigations impact on the LST is greater than during the wet year; all mean differences are significant $(p<0.01)$ except for "**". See Table 2 for mean differences for all land cover types.

Table 2. Mean differences between high and low irrigation rates for dry (WY20002) and wet (WY2005) years for each month and land cover type.

\begin{tabular}{|c|c|c|c|c|c|c|c|c|}
\hline \multirow{2}{*}{$\begin{array}{c}\text { Land Cover } \\
\text { Month }\end{array}$} & \multicolumn{2}{|c|}{ Open Space } & \multicolumn{2}{|c|}{ Low Intensity } & \multicolumn{2}{|c|}{ Med. Intensity } & \multicolumn{2}{|c|}{ High Intensity } \\
\hline & Dry & Wet & Dry & Wet & Dry & Wet & Dry & Wet \\
\hline October & -3.9 & -1.9 & -2.1 & -1.9 & -2.7 & -2.5 & -0.6 & -1.2 \\
\hline November & -0.6 & -0.9 & -0.4 & -0.8 & -0.7 & -1.5 & * & -0.9 \\
\hline December & -1.3 & -1.1 & -1.0 & -1.0 & -1.4 & -1.3 & * & -0.8 \\
\hline January & -2.3 & * & -1.0 & $*$ & -1.1 & * & * & $*$ \\
\hline February & -1.3 & * & -1.3 & * & -1.6 & -1.2 & -0.6 & -0.3 \\
\hline March & -1.4 & * & -1.6 & * & -2.5 & -1.9 & -1.4 & -1.4 \\
\hline April & -2.4 & -0.7 & -2.5 & -0.9 & -3.4 & -1.4 & -1.2 & * \\
\hline May & -2.8 & -0.8 & -3.0 & -1.3 & -3.8 & -2.4 & -1.7 & -0.6 \\
\hline June & -2.6 & -1.7 & -2.8 & -2.4 & -3.5 & -3.7 & -1.2 & -2.0 \\
\hline July & -2.6 & -1.2 & -3.2 & -1.9 & -3.7 & -2.2 & -1.9 & -1.0 \\
\hline August & -2.6 & -1.7 & -3.0 & -2.3 & -3.4 & -2.6 & -1.6 & -1.4 \\
\hline September & -2.5 & -1.3 & -3.0 & -2.1 & -3.2 & -2.4 & -1.3 & -1.2 \\
\hline
\end{tabular}

* Mean difference not statistically significant $(p>0.01)$.

\subsection{Simulated LST Change}

An integrated hydrologic and land surface model is used to simulate the effects of 13 irrigation volumes (Table 1) and 4 irrigation times of the day on the fluxes produced by the four urban LC types during our study period. Hourly LST results for each of the urban LCs from these simulations are compared to the values estimated for each of the 364 scenes in our study period (Figure 4). Our model generally underestimates LST by $-6.5 \mathrm{~K}$ in developed open space up to $-11.1 \mathrm{~K}$ for high intensity developed which has also been shown to be the case in other studies utilizing similar models. There are three possible sources for this bias: (1) errors in remote sensing retrieval and subsequent calculation of LST; (2) uncertainty in emissivity estimation and mixing model methodology (see Section 2.2; and (3) challenges in urban land surface parameterization in land surface models. Eliminating this linear bias in our modeling results improves agreement between simulations and observations to an $R^{2}$ range of $0.43-0.70$. 


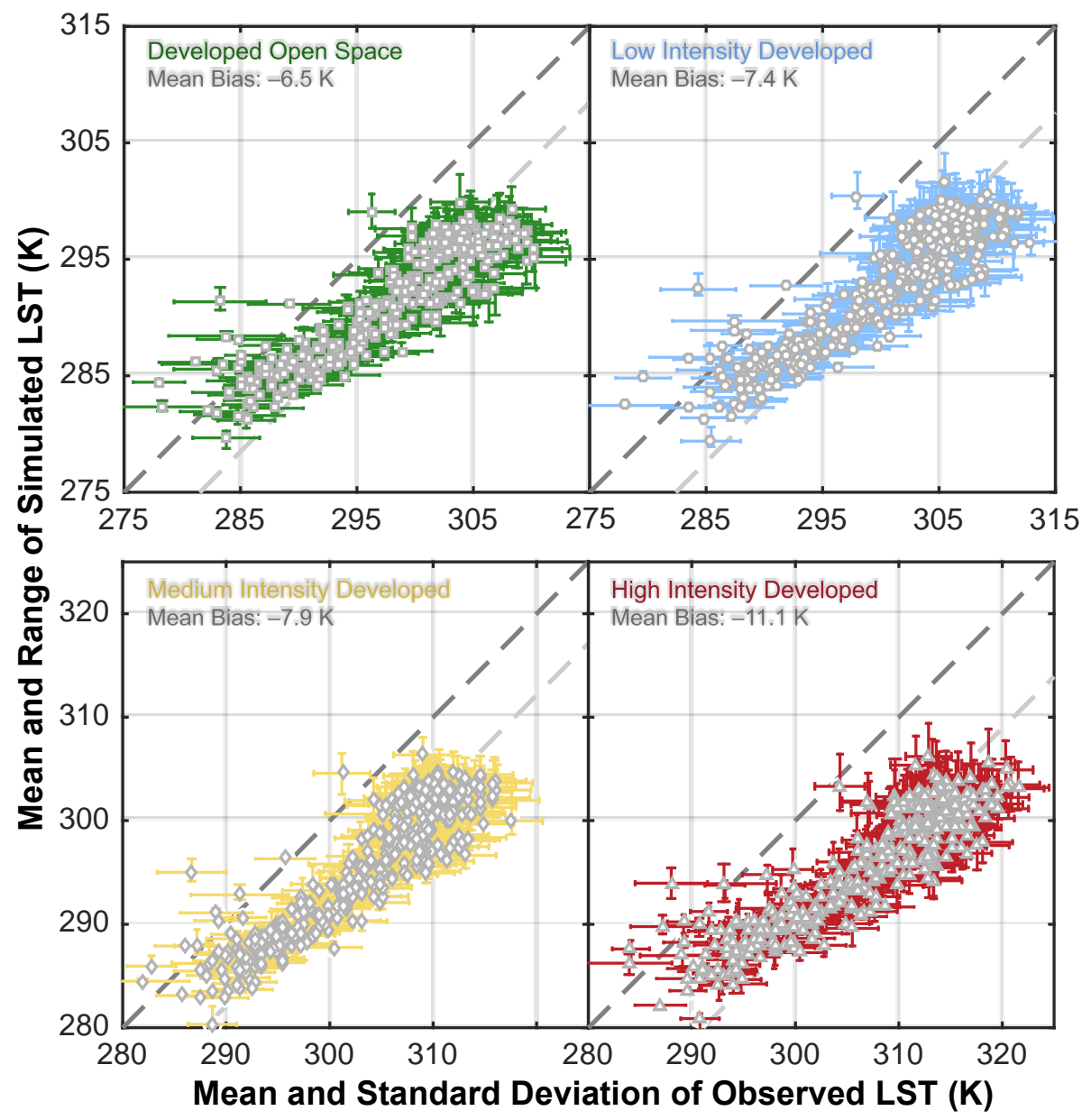

Figure 4. Comparison of simulated and observed Landsat LST for all overpass times. Horizontal bars represent the standard deviation of values observed for that scene; vertical bars represent the full range of model results from all simulations. 1:1 and mean bias lines shown as dark and light grey dashed lines, respectively.

More important to this work is the relative change in LST between the low irrigation and high irrigation simulations. To evaluate, we compare the mean LST differences between high and low water use areas (similar to Figures 2 and 3) to the modeled mean differences between the best-fit irrigation volume scenarios, all aggregated by month and LC (Figure 5). The best-fit irrigation scenarios are found by calculating the monthly mean LST difference between each combination of low to higher irrigation rate. This, effectively, provides an indirect estimation of the irrigation rates of low and high irrigated areas for our study period and domain, which are found to be low $\rightarrow$ high scenarios (Table 1) $+5 \% \rightarrow+50 \%$, Base $\rightarrow+300 \%,+25 \% \rightarrow+300 \%$, and $+25 \% \rightarrow+300 \%$ for high, medium, low intensity developed and developed open space, respectively. However, due to the simulated constant irrigation rate throughout the year, the LST change during the spring months are consistently underestimated. Removing these underestimated spring months (March, April, May) alone increases the agreement between modeled and observed mean LST difference $\left(R^{2}\right.$ values increase from a range of $0.23-0.64$ to $0.70-0.85$ ). Our model is also able to capture the relative impact of irrigation on the LST of different LCs. The LCs most impacted by the irrigation flux are the medium and low intensity developed LC, while smaller LST changes occur in developed open space and high intensity developed LC. Since our model is capturing relative change in LST caused by irrigation, we continue with an analysis of the impacts on hydrologic fluxes in the following section. 


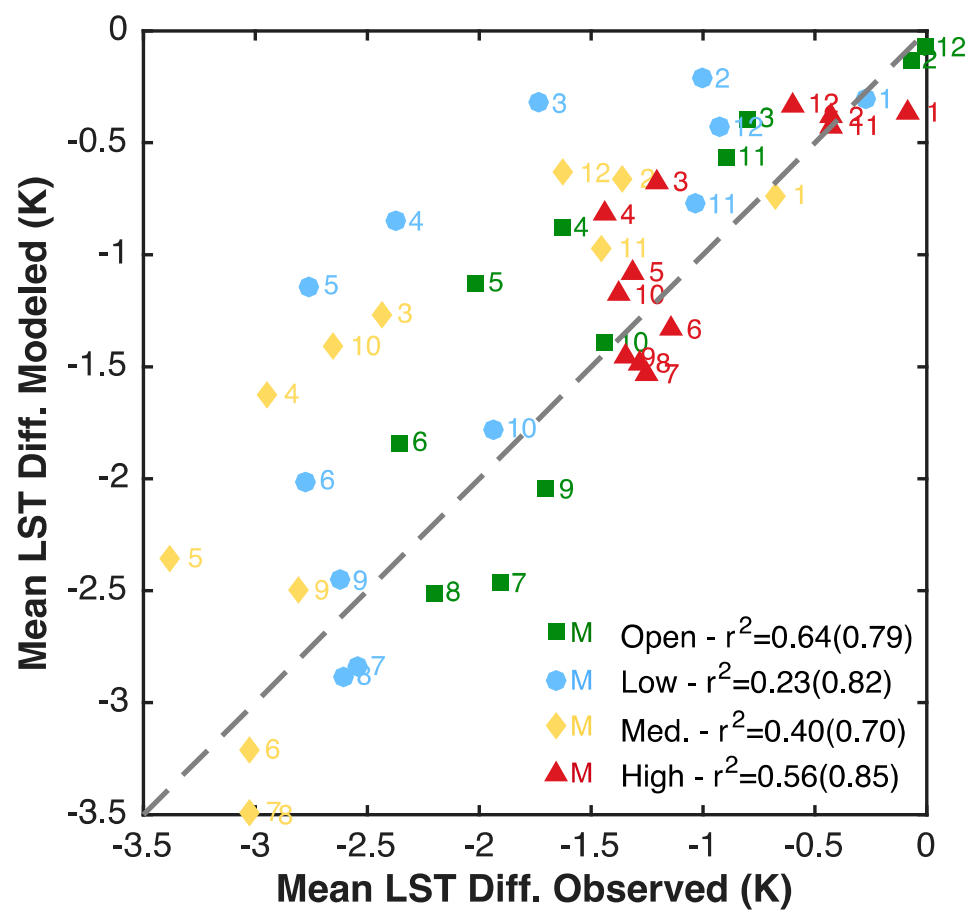

Figure 5. Mean LST differences between low and high irrigation in Landsat LST vs. modeled simulations for each month. These are calculated using the low and high irrigation areas and simulation scenarios aggregated through the study period by month similar to Figures 2 and 3 . The $r^{2}$ values along the 1:1 line are shown with and without spring months $(3,4,5)$ included in the calculation.

\subsection{Sensitivities of Hydrologic Fluxes and Regime Change}

Utilizing our model simulations, we identify the impacts of the various irrigation volumes and timings on the mean total runoff and ET produced by the urban LC (Figure 6). Developed high intensity LC is not analyzed due to the observed findings of very low irrigation rates for this LC type ( $+5 \% \rightarrow+50 \%$, low $\rightarrow$ high irrigation rates). At lower volumes, most of the irrigation volume is partitioned into ET while runoff remains relatively stable until an inflection point is reached at the $+75 \%$ irrigation rate for medium and low intensity developed, and the $+125 \%$ irrigation rate for developed open space. At these points, runoff begins to increase as ET plateaus consistent with the different energy limitations of each LC. The effect of irrigation timing is found to be insignificant as compared to irrigation volume with a maximum change of $\pm 2 \%$ of mean runoff and ET. We note that irrigation is added to the simulations without assessing any potential associated impacts on air temperature or humidity (which are inputs to the model).

Budyko and water-energy partitioning plots are used to assess the general impact of the irrigation flux on the hydrologic regime-defined here as the general pattern of runoff, ET, and infiltration in a given domain. We calculate the evaporative index (ET/P), aridity index (PET/P), and evaporative efficiency (ET/PET) for our domain for the full 11-year simulation and modify the precipitation value by adding the total irrigation volume to the calculation for each ( $\mathrm{P}+\mathrm{Irr}$.); this allows us to assess the impact of irrigation within the traditional spaces of the Budyko and water-energy partitioning frameworks. The aridity index of the irrigation scenarios crosses the semi-arid/sub-humid regime threshold (Figure $7 \mathrm{a}$ ) with irrigation rates of only $\sim+75 \%$ of precipitation for these LCs, yet higher irrigation volumes are common across Los Angeles. As irrigation increases, the change in climatic regime has large implications for increased runoff and potential recharge rates within the domain. The changes occurring at lower irrigation volumes cause shifts along slopes of similar aridity in the water-energy partitioning space (Figure $7 b$ ) pointing to changes in the inherent behavior of the LC caused by the change in land use [39], attributable to increases in vegetation. At higher irrigation rates, evaporative efficiency remains fairly constant (Figure $7 \mathrm{~b}$ ) as the energy limit is reached. The additional 
water in the system is increasingly partitioned into runoff and potential recharge rather than to ET and vegetation growth indicating the irrigation rates at which inefficiencies occur in outdoor water use in Los Angeles for these LC types.
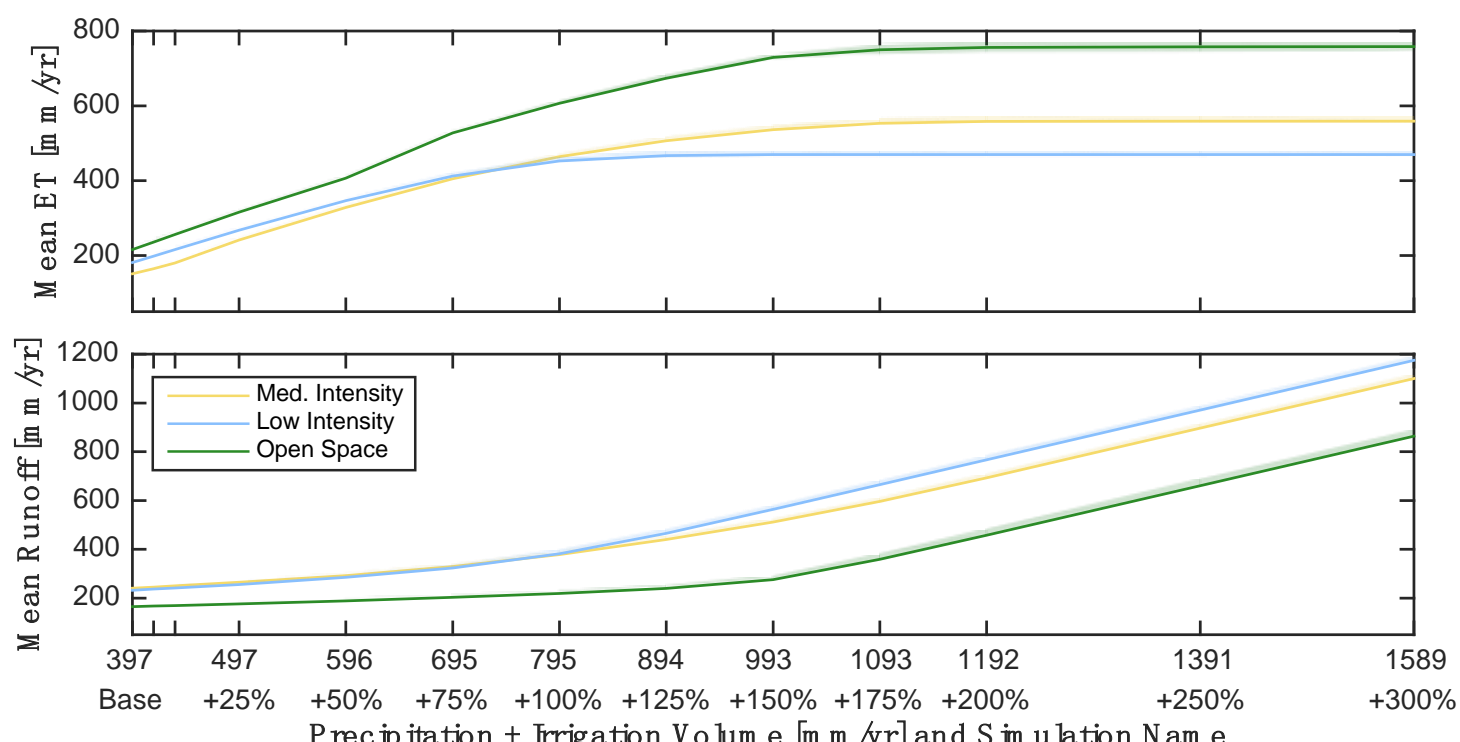

Figure 6. Study-period mean simulated evapotranspiration and runoff. All simulated irrigation timings and volumes for the study period are shown. The shading represents the range of timing, which is small throughout with the largest range seen for the open space LC at $+300 \%$ simulation.
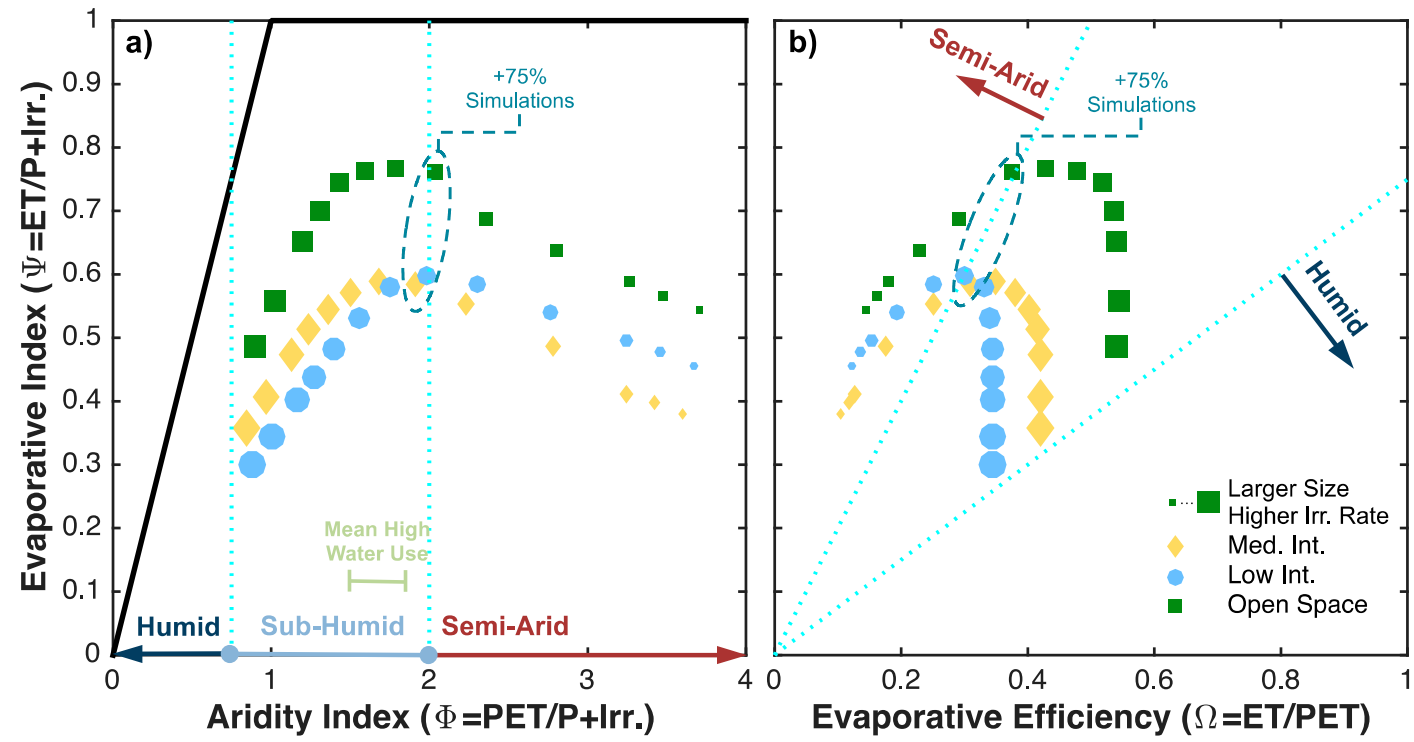

Figure 7. Budyko and water-energy plots for simulations. Full study period mean modified (a) aridity index vs. evaporative index and (b) evaporative efficiency vs. evaporative index for each irrigation volume (mean of all irrigation timings). Irrigation volume is represented by size of symbol and the "mean" high water use area volumes (middle $50 \%$ of high irrigation rates for domain and time period) are shown in (a). Black lines in (a) are the theoretical water and energy limits and the dotted blue lines are transition points in aridity $[85,86]$.

\section{Discussion and Conclusions}

By leveraging the strengths of remote sensing, integrated hydrologic and land surface modeling, and analysis of municipal water use data, this study captures the important relationships between outdoor water use, LST, and hydrologic regimes. Specifically, we first conducted an analysis using 
Landsat-based observations of LST and a unique municipal water use dataset to understand impacts of outdoor water use on LST. Next, a coupled integrated hydrologic and land surface model was utilized to complete a sensitivity study of irrigation on land surface and hydrologic fluxes. This allowed for a comparison of modeling output and remote sensing data as well as an analysis of how the hydrologic regime changes due to outdoor water use. We find that:

1. LST decreases with higher outdoor water use within similar LC type throughout our study period and at all times of the year. A larger impact on LST is seen in the spring and summer months, hypothesized to be a result of both larger irrigation volumes and increased prevailing LST during these months. Furthermore, by analyzing the LST difference during a wet year and a dry year we conclude that the cooling effect is largely caused by the irrigation flux, rather than any changes in regional meteorology.

2. We are able to capture the relative change in LST caused by irrigation given that our simulations implement a constant irrigation pattern as opposed to higher irrigation rates in the spring and summer months. Furthermore, we capture the observed relative behavior of each urban LC type indicating fairly realistic representation of the urban land surface using our parameterization. However, these models consistently underestimate LST as compared to values of remotely sensed LST throughout the study period and for each LC type, with more developed LCs causing larger biases. This points to possible systematic errors in both model parameterization and in the method used to estimate LST from the remote sensing observations.

3. The urban irrigation flux causes significant changes to the hydrologic regime of the urban semi-arid environment. The timing of irrigation only has a small impact on hydrologic fluxes for urban LC; the largest impact ( $\pm 2 \%$ ) occurs at high irrigation volumes for developed open space. At low volumes (less than $~ 75 \%$ of mean precipitation), the irrigation flux is partitioned into ET and into vegetation growth with runoff held relatively constant. At higher volumes, closer to estimated values in Los Angeles for the study period, the flux moves the system into a sub-humid regime with implications for increased runoff and infiltration. The model results presented here show some deficiencies in recreation of land surface temperatures by the land surface model used. However, adding the irrigation flux is shown to have a clear advantage in simulating the difference in LST between high and low water use areas of otherwise similar land cover.

The interconnected nature of the terrestrial hydrologic and energy cycles is well documented in the literature, yet many urban water sustainability plans fail to consider these realities. We hope that further quantification of the ways in which changes in water use, for instance, impact local groundwater, runoff, temperatures, and other environmentally important metrics will help in creating holistic plans for policy makers to manage their cities in a sustainable manner. For Ballona Creek watershed, and Los Angeles in general, long-term water use plans should be implemented with an understanding of these interactions with groundwater levels, possible changes in pollution concentration in runoff, and temperature increases shown in this study. This work provides further impetus for the inclusion of urban heterogeneity and the irrigation flux in hydrologic studies, especially studies in urban semi-arid regions. These insights into the effects of irrigation in semi-arid urban settings are significant, yet further work is needed at the watershed scale to evaluate the impacts of local water conservation plans, the significance of irrigation fluxes on local water resources, and changes to the microclimate.

Author Contributions: Conceptualization, B.R.; Data curation, B.R.; Formal analysis, B.R.; Funding acquisition, T.H. and R.M.; Investigation, B.R.; Methodology, B.R., T.H. and R.M.; Project administration, T.H. and R.M.; Resources, T.H.; Software, R.M.; Supervision, T.H. and R.M.; Visualization, B.R.; Writing: original draft, B.R.; Writing: review and editing, T.H. and R.M.

Funding: This research was funded in part by a National Science Foundation (NSF) Graduate Research Fellowship (DGE-1057607), NSF Water Sustainability and Climate Grants (EAR-12040235, EAR-1204787), and the NSF Engineering Research Center for Reinventing the Nation's Urban Water Infrastructure (ReNUWIt.org; EEC-1028968). 
Acknowledgments: We thank Jennifer L. Jefferson and Lindsay A. Bearup for their comments and review of the manuscript prior to submission and the two anonymous reviewers during the review process. We would also like to thank NASA and the USGS for making the Landsat data publicly available and the Los Angeles Department of Water and Power for the water use data.

Conflicts of Interest: The authors declare no conflict of interest.

\section{References}

1. Friedman, K.; Heaney, J.P.; Morales, M.; Palenchar, J.E. Predicting and managing residential potable irrigation using parcel-level databases. J. Am. Water Works Assoc. 2013, 105, E372-E386. [CrossRef]

2. Mini, C.; Hogue, T.S.; Pincetl, S. Estimation of residential outdoor water use in Los Angeles, California. Landsc. Urban Plan. 2014, 127, 124-135. [CrossRef]

3. United Nations. World Urbanization Prospects; United Nations Population Division, Department of Economic and Social Affairs: New York, NY, USA, 2011.

4. Kaushal, S.; McDowell, W.; Wollheim, W.; Johnson, T.; Mayer, P.; Belt, K.; Pennino, M.; Kaushal, S.S.; McDowell, W.H.; Wollheim, W.M.; et al. Urban Evolution: The Role of Water. Water 2015, 7, 4063-4087. [CrossRef]

5. Kim, H.; Son, J.; Lee, S.; Koop, S.; van Leeuwen, K.; Choi, Y.; Park, J.; Kim, H.; Son, J.; Lee, S.; et al. Assessing Urban Water Management Sustainability of a Megacity: Case Study of Seoul, South Korea. Water 2018, 10, 682. [CrossRef]

6. Feingold, D.; Koop, S.; van Leeuwen, K. The City Blueprint Approach: Urban Water Management and Governance in Cities in the U.S. Environ. Manag. 2018, 61, 9-23. [CrossRef] [PubMed]

7. Mini, C.; Hogue, T.S.; Pincetl, S. Patterns and controlling factors of residential water use in Los Angeles, California. Water Policy 2014, 16, 1054-1069. [CrossRef]

8. Bonfils, C.; Lobell, D. Empirical evidence for a recent slowdown in irrigation-induced cooling. PNAS 2007, 104, 13582-13587. [CrossRef] [PubMed]

9. Kueppers, L.M.; Snyder, M.A.; Sloan, L.C. Irrigation cooling effect: Regional climate forcing by land-use change. Geophys. Res. Lett. 2007, 34, L03703. [CrossRef]

10. Lobell, D.B.; Bonfils, C.J.; Kueppers, L.M.; Snyder, M.A. Irrigation cooling effect on temperature and heat index extremes. Geophys. Res. Lett. 2008, 35, L09705. [CrossRef]

11. Puma, M.J.; Cook, B.I. Effects of irrigation on global climate during the 20th century. J. Geophys. Res. Atmos. 2010, 115, D16120. [CrossRef]

12. Sorooshian, S.; Li, J.; Hsu, K.; Gao, X. How significant is the impact of irrigation on the local hydroclimate in California's Central Valley? Comparison of model results with ground and remote-sensing data. J. Geophys. Res. Atmos. 2011, 116, D06102. [CrossRef]

13. Sorooshian, S.; AghaKouchak, A.; Li, J. Influence of Irrigation on Land Hydrological Processes over California: Influence of Irrigation on hydrology. J. Geophys. Res. Atmos. 2014, 119, 137-152. [CrossRef]

14. Lu, Y.; Kueppers, L. Increased heat waves with loss of irrigation in the United States. Environ. Res. Lett. 2015, 10, 064010. [CrossRef]

15. Jaeger, E.B.; Seneviratne, S.I. Impact of soil moisture-atmosphere coupling on European climate extremes and trends in a regional climate model. Clim. Dyn. 2011, 36, 1919-1939. [CrossRef]

16. Kollet, S.J.; Maxwell, R.M. Capturing the influence of groundwater dynamics on land surface processes using an integrated, distributed watershed model. Water Resour. Res. 2008, 44, W02402. [CrossRef]

17. Maxwell, R.M.; Kollet, S.J. Interdependence of groundwater dynamics and land-energy feedbacks under climate change. Nat. Geosci. 2008, 1, 665-669. [CrossRef]

18. Seneviratne, S.I.; Corti, T.; Davin, E.L.; Hirschi, M.; Jaeger, E.B.; Lehner, I.; Orlowsky, B.; Teuling, A.J. Investigating soil moisture-climate interactions in a changing climate: A review. Earth-Sci. Rev. 2010, 99, 125-161. [CrossRef]

19. Sharp, J.M.; Krothe, J.N.; Mather, J.D.; Garcia-Fresca, B.; Stewart, C.A. Effects of Urbanization on Groundwater Systems. In Earth Science in the City: A Reader; Heiken, G., Fakundiny, R., Sutter, J., Eds.; American Geophysical Union: Washington, DC, USA, 2003; pp. 257-278.

20. Garcia-Fresca, B.; Sharp, J.M. Hydrogeologic considerations of urban development: Urban-induced recharge. Rev. Eng. Geol. 2005, 16, 123-136. [CrossRef] 
21. Sharp, J.M. The impacts of urbanization on groundwater systems and recharge. AQUA Mundi 2010, 1, 51-56. [CrossRef]

22. Hibbs, B.J.; Sharp, J.M. Hydrogeological Impacts of Urbanization. Environ. Eng. Geosci. 2012, 18, 3-24. [CrossRef]

23. Passarello, M.C.; Sharp, J.M.; Pierce, S.A. Estimating Urban-Induced Artificial Recharge: A Case Study for Austin, TX. Environ. Eng. Geosci. 2012, 18, 25-36. [CrossRef]

24. Bhaskar, A.S.; Welty, C. Water Balances along an Urban-to-Rural Gradient of Metropolitan Baltimore, 2001-2009. Environ. Eng. Geosci. 2012, 18, 37-50. [CrossRef]

25. Bhaskar, A.S.; Welty, C.; Maxwell, R.M.; Miller, A.J. Untangling the effects of urban development on subsurface storage in Baltimore. Water Resour. Res. 2015, 51, 1158-1181. [CrossRef]

26. Lerner, D.N. Groundwater Recharge in Urban Areas. Atmos. Environ. 1990, 24, 29-33. [CrossRef]

27. Lerner, D.N. Identifying and quantifying urban recharge: A review. Hydrogeol. J. 2002, 10, 143-152. [CrossRef]

28. Delleur, J.W. The evolution of urban hydrology: Past, present, and future. J. Hydraul. Eng. 2003, 129, 563-573. [CrossRef]

29. Fletcher, T.D.; Andrieu, H.; Hamel, P. Understanding, management and modelling of urban hydrology and its consequences for receiving waters: A state of the art. Adv. Water Resour. 2013, 51, 261-279. [CrossRef]

30. Schirmer, M.; Leschik, S.; Musolff, A. Current research in urban hydrogeology-A review. Adv. Water Resour. 2013, 51, 280-291. [CrossRef]

31. Barrett, M.H.; Hiscock, K.M.; Pedley, S.; Lerner, D.N.; Tellam, J.H.; French, M.J. Marker species for identifying urban groundwater recharge sources: A review and case study in Nottingham, UK. Water Res. 1999, 33, 3083-3097. [CrossRef]

32. Yang, Y.; Lerner, D.N.; Barrett, M.H.; Tellam, J.H. Quantification of groundwater recharge in the city of Nottingham, UK. Environ. Geol. 1999, 38, 183-198. [CrossRef]

33. Barron, O.V.; Barr, A.D.; Donn, M.J. Effect of urbanisation on the water balance of a catchment with shallow groundwater. J. Hydrol. 2013, 485, 162-176. [CrossRef]

34. Bhaskar, A.S.; Beesley, L.; Burns, M.J.; Fletcher, T.D.; Hamel, P.; Oldham, C.E.; Roy, A.H. Will it rise or will it fall? Managing the complex effects of urbanization on base flow. Freshw. Sci. 2016, 35, 293-310. [CrossRef]

35. Vahmani, P.; Hogue, T.S. High-resolution land surface modeling utilizing remote sensing parameters and the Noah UCM: a case study in the Los Angeles Basin. Hydrol. Earth Syst. Sci. 2014, 18, 4791-4806. [CrossRef]

36. Vahmani, P.; Hogue, T.S. Incorporating an Urban Irrigation Module into the Noah Land Surface Model Coupled with an Urban Canopy Model. J. Hydrometeorol. 2014, 15, 1440-1456. [CrossRef]

37. Lintner, B.R.; Gentine, P.; Findell, K.L.; Salvucci, G.D. The Budyko and complementary relationships in an idealized model of large-scale land-atmosphere coupling. Hydrol. Earth Syst. Sci. 2015, 19, 2119-2131. [CrossRef]

38. Wang, C.; Wang, S.; Fu, B.; Zhang, L. Advances in hydrological modelling with the Budyko framework A review. Prog. Phys. Geogr. 2016, 40, 409-430. [CrossRef]

39. Renner, M.; Brust, K.; Schwärzel, K.; Volk, M.; Bernhofer, C. Separating the effects of changes in land cover and climate: A hydro-meteorological analysis of the past $60 \mathrm{yr}$ in Saxony, Germany. Hydrol. Earth Syst. Sci. 2014, 18, 389-405. [CrossRef]

40. Jaramillo, F.; Destouni, G. Developing water change spectra and distinguishing change drivers worldwide. Geophys. Res. Lett. 2014, 41, 8377-8386. [CrossRef]

41. Taha, H. Urban climates and heat islands: Albedo, evapotranspiration, and anthropogenic heat. Energy Build. 1997, 25, 99-103. [CrossRef]

42. Arnfield, A.J. Two decades of urban climate research: A review of turbulence, exchanges of energy and water, and the urban heat island. Int. J. Clim. 2003, 23, 1-26. [CrossRef]

43. Masson, V. Urban surface modeling and the meso-scale impact of cities. Theor. Appl. Climatol. 2006, 84, 35-45. [CrossRef]

44. Roth, M. Review of urban climate research in (sub)tropical regions. Int. J. Clim. 2007, 27, 1859-1873. [CrossRef]

45. Lamptey, B. An analytical framework for estimating the urban effect on climate. Int. J. Clim. 2010, 30, 72-88. [CrossRef]

46. Wang, J.; Feng, J.; Yan, Z.; Hu, Y.; Jia, G. Nested high-resolution modeling of the impact of urbanization on regional climate in three vast urban agglomerations in China. J. Geophys. Res. Atmos. 2012, 117. [CrossRef] 
47. Zhao, L.; Lee, X.; Smith, R.B.; Oleson, K. Strong contributions of local background climate to urban heat islands. Nature 2014, 511, 216-219. [CrossRef] [PubMed]

48. Taleghani, M.; Sailor, D.; Ban-Weiss, G.A. Micrometeorological simulations to predict the impacts of heat mitigation strategies on pedestrian thermal comfort in a Los Angeles neighborhood. Environ. Res. Lett. 2016, 11, 024003. [CrossRef]

49. Vahmani, P.; Ban-Weiss, G. Climatic consequences of adopting drought tolerant vegetation over Los Angeles as a response to California drought. Geophys. Res. Lett. 2016, 43, 8240-8249. [CrossRef]

50. Kumar, R.; Mishra, V.; Buzan, J.; Kumar, R.; Shindell, D.; Huber, M. Dominant control of agriculture and irrigation on urban heat island in India. Sci. Rep. 2017, 7, 14054. [CrossRef] [PubMed]

51. Collier, C.G. The impact of urban areas on weather. Q. J. Roy. Meteorol. Soc. 2006, 132, 1-25. [CrossRef]

52. Fischer, E.M.; Oleson, K.W.; Lawrence, D.M. Contrasting urban and rural heat stress responses to climate change. Geophys. Res. Lett. 2012, 39, L03705. [CrossRef]

53. Li, D.; Bou-Zeid, E. Quality and sensitivity of high-resolution numerical simulation of urban heat islands. Environ. Res. Lett. 2014, 9, 055001. [CrossRef]

54. Bounoua, L.; Zhang, P.; Mostovoy, G.; Thome, K.; Masek, J.; Imhoff, M.; Marshall, S.; Quattrochi, D.; Santanello, J.; Silva, J.; Wolfe, R.; et al. Impact of urbanization on US surface climate. Environ. Res. Lett. 2015, 10, 084010. [CrossRef]

55. Liu, S.; Hogue, T.S.; Stein, E.D.; Barco, J. Contempory and Historical Hydrologic Analysis of the Ballona Creek Watershed; Southern California Coastal Water Research Project: Costa Mesa, CA, USA, 2011; p. 49.

56. LADWP. 2010 Urban Water Management Plan; Los Angeles Department of Water and Power: Los Angeles, CA, USA, 2010; p. 539.

57. Masek, J.G.; Vermote, E.F.; Saleous, N.E.; Wolfe, R.; Hall, F.G.; Huemmrich, K.F.; Gao, F.; Kutler, J.; Lim, T.-K. A Landsat surface reflectance dataset for North America, 1990-2000. IEEE Geosci. Remote Sens. Lett. 2006, 3, 68-72. [CrossRef]

58. Artis, D.A.; Carnahan, W.H. Survey of emissivity variability in thermography of urban areas. Remote Sens. Environ. 1982, 12, 313-329. [CrossRef]

59. Sobrino, J.A.; Jiménez-Muñoz, J.C.; Paolini, L. Land surface temperature retrieval from LANDSAT TM 5. Remote Sens. Environ. 2004, 90, 434-440. [CrossRef]

60. Stathopoulou, M.; Cartalis, C.; Petrakis, M. Integrating Corine Land Cover data and Landsat TM for surface emissivity definition: application to the urban area of Athens, Greece. Int. J. Remote Sens. 2007, 28, 3291-3304. [CrossRef]

61. Homer, C.; Dewitz, J.; Fry, J.; Coan, M.; Hossain, N.; Larson, C.; Herold, N.; McKerrow, A.; VanDriel, J.N.; Wickham, J. Completion of the 2001 National Land Cover Database for the conterminous United States. Photogramm. Eng. Remote Sens. 2007, 73, 337-341.

62. Fry, J.A.; Xian, G.; Jin, S.; Dewitz, J.A.; Homer, C.G.; Yang, L.; Barnes, C.A.; Herold, N.D.; Wickham, J.D. Completion of the 2006 National Land Cover Database for the conterminous United States. Photogramm. Eng. Remote Sens. 2011, 77, 858-864.

63. Gleick, P.H.; Wolff, G.H.; Cushing, K.K. Waste Not, Want Not: The Potential for Urban Water Conservation in California; Pacific Institute for Studies in Development, Environment, and Security: Oakland, CA, USA, 2003; ISBN 1-893790-09-6.

64. Maxwell, R.M.; Miller, N.L. Development of a Coupled Land Surface and Groundwater Model. J. Hydrometeorol. 2005, 6, 233-247. [CrossRef]

65. Jefferson, J.L.; Gilbert, J.M.; Constantine, P.G.; Maxwell, R.M. Active subspaces for sensitivity analysis and dimension reduction of an integrated hydrologic model. Comput. Geosci. 2015, 83, 127-138. [CrossRef]

66. Jefferson, J.L.; Maxwell, R.M. Evaluation of simple to complex parameterizations of bare ground evaporation. J. Adv. Model. Earth Syst. 2015, 7, 1075-1092. [CrossRef]

67. Ferguson, I.M.; Jefferson, J.L.; Maxwell, R.M.; Kollet, S.J. Effects of root water uptake formulation on simulated water and energy budgets at local and basin scales. Environ. Earth Sci. 2016, 75, 1-15. [CrossRef]

68. Ashby, S.F.; Falgout, R.D. A parallel multigrid preconditioned conjugate gradient algorithm for groundwater flow simulations. Nucl. Sci. Eng. 1996, 124, 145-159. [CrossRef]

69. Jones, J.E.; Woodward, C.S. Newton-Krylov-multigrid solvers for large-scale, highly heterogeneous, variably saturated flow problems. Adv. Water Resour. 2001, 24, 763-774. [CrossRef] 
70. Kollet, S.J.; Maxwell, R.M. Integrated surface-groundwater flow modeling: A free-surface overland flow boundary condition in a parallel groundwater flow model. Adv. Water Resour. 2006, 29, 945-958. [CrossRef]

71. Maxwell, R.M. A terrain-following grid transform and preconditioner for parallel, large-scale, integrated hydrologic modeling. Adv. Water Resour. 2013, 53, 109-117. [CrossRef]

72. Dai, Y.; Zeng, X.; Dickinson, R.E.; Baker, I.; Bonan, G.B.; Bosilovich, M.G.; Denning, A.S.; Dirmeyer, P.A.; Houser, P.R.; Niu, G.; et al. The Common Land Model. Bull. Am. Meteorol. Soc. 2003, 84, 1013-1023. [CrossRef]

73. Zeng, X.; Shaikh, M.; Dai, Y.; Dickinson, R.E.; Myneni, R. Coupling of the Common Land Model to the NCAR Community Climate Model. J. Clim. 2002, 15, 1832-1854. [CrossRef]

74. Richards, L.A. Capillary Conduction of Liquids through Porous Mediums. Physics 1931, 1, 318-333. [CrossRef]

75. Ferguson, I.M.; Maxwell, R.M. Hydrologic and land-energy feedbacks of agricultural water management practices. Environ. Res. Lett. 2011, 6, 014006. [CrossRef]

76. Condon, L.E.; Maxwell, R.M. Feedbacks between managed irrigation and water availability: Diagnosing temporal and spatial patterns using an integrated hydrologic model. Water Resour. Res. 2014, 50, 2600-2616. [CrossRef]

77. Condon, L.E.; Maxwell, R.M. Groundwater-fed irrigation impacts spatially distributed temporal scaling behavior of the natural system: A spatio-temporal framework for understanding water management impacts. Environ. Res. Lett. 2014, 9, 034009. [CrossRef]

78. Reyes, B.; Maxwell, R.M.; Hogue, T.S. Impact of lateral flow and spatial scaling on the simulation of semi-arid urban land surfaces in an integrated hydrologic and land surface model. Hydrol. Process. 2016, 30, 1192-1207. [CrossRef]

79. Ajami, H.; McCabe, M.F.; Evans, J.P.; Stisen, S. Assessing the impact of model spin-up on surface water-groundwater interactions using an integrated hydrologic model. Water Resour. Res. 2014, 50, 2636-2656. [CrossRef]

80. Mitchell, K.E.; Lohmann, D.; Houser, P.R.; Wood, E.F.; Schaake, J.C.; Robock, A.; Cosgrove, B.A.; Sheffield, J.; Duan, Q.; Luo, L.; et al. The multi-institution North American Land Data Assimilation System (NLDAS): Utilizing multiple GCIP products and partners in a continental distributed hydrological modeling system. J. Geophys. Res. Atmos. 2004, 109, D7. [CrossRef]

81. Ly, S.; Charles, C.; Degré, A. Geostatistical interpolation of daily rainfall at catchment scale: The use of several variogram models in the Ourthe and Ambleve catchments, Belgium. Hydrol. Earth Syst. Sci. 2011, 15, 2259-2274. [CrossRef]

82. Gesch, D.; Oimoen, M.; Greenlee, S.; Nelson, C.; Steuck, M.; Tyler, D. The national elevation dataset. Photogramm. Eng. Remote Sens. 2002, 68, 5-11.

83. Cayan, D.R.; Maurer, E.P.; Dettinger, M.D.; Tyree, M.; Hayhoe, K. Climate change scenarios for the California region. Clim. Chang. 2008, 87, 21-42. [CrossRef]

84. Mini, C.; Hogue, T.S.; Pincetl, S. The effectiveness of water conservation measures on summer residential water use in Los Angeles, California. Resour. Conserv. Recycl. 2015, 94, 136-145. [CrossRef]

85. Ponce, V.M.; Pandey, R.P.; Ercan, S. Characterization of Drought across Climatic Spectrum. J. Hydrol. Eng. 2000, 5, 222-224. [CrossRef]

86. Arora, V.K. The use of the aridity index to assess climate change effect on annual runoff. J. Hydrol. 2002, 265, 164-177. [CrossRef]

(C) 2018 by the authors. Licensee MDPI, Basel, Switzerland. This article is an open access article distributed under the terms and conditions of the Creative Commons Attribution (CC BY) license (http:/ / creativecommons.org/licenses/by/4.0/). 